\title{
Tendon Transfers Around Wrist in Cases of Obstetric Brachial Plexus Injury
}

\author{
MOHAMMED A. MOHAMMED, M.Sc.; TAREK A. EL-GAMMAL, M.D.; AMR EL-SAYED, M.D. and \\ MOHAMED M. KOTB, M.D.
}

The Department of Orthopedic \& Trauma Surgery, Faculty of Medicine, Assiut University

\begin{abstract}
Background: Wrist extension is essential in the development of motor skills in young children. Adequate wrist extension is important for good grip function of the hand, as a slightly extended wrist results in a better and stronger grip.

Material and Methods: This prospective series reports on 32 patients with sequlae obstetric brachial plexus injury who underwent tendon transfer around wrist. The mean age at time of transfer was 9.9 years. FCU tendon was utilized in 25 cases, PT in 3 cases, BR in 2 cases, PL in 1 case and FDS in 1 case. The recipient tendon was ECRB in 14 cases, EDC in 12 cases, ECRL in 2 cases EPL in 2 cases, and FPL in 2 cases. Raimondi score, Toronto scale, Medical research council muscle grading system, Range of motion and hand grip strength were used to evaluate results. Good results (MRC grading of 4) were obtained in 24 cases $(75 \%)$.

Conclusion: Tendon transfers around wrist are considered good operative option in cases of sequlae of obstetric brachial plexus injury for restoration of hand function with or without other procedures tailored to the need of every case.
\end{abstract}

Key Words: Tendon transfer - Brachial plexus - Around wrist.

\section{Introduction}

RESTORATION of wrist and hand function in children is essential in development of motor skills. Most of function of upper limb is meant for hand function. Options available are limited given the fact that child is already in a deficit; lack of dispensable donors [2] . persistent loss of active wrist extension is seen in infants with both upper/middle $(\mathrm{C} 5 / \mathrm{C} 6 / \mathrm{C} 7)$ brachial plexus birth injuries and in those with global (C5-T1) injuries [3]. Although previous studies about the subject of tendon transfer

Correspondence to: Dr. Mohammed A. Mohammed,

The Department of Orthopedic \& Trauma Surgery, Faculty of Medicine, Assiut University to restore wrist extension do exist, this study is concerned with tendon transfer for improvement of hand function including fingers and wrist, not only wrist extension. The potential presence of multiple denervated muscle groups and the inherent difficulty associated with assessment of clinical and functional losses in young children make them a challenging patient population [4].

\section{Patients and Methods}

Thirty two patients underwent tendon transfer around wrist for improvement of wrist and hand function in microsurgery unit of Assiut University Hospital, were studied between 2015 and 2017 in a prospective series. Patient characteristics, such as age, sex, type of birth palsy, type of tendon transfer, as well as complications and results, were documented. The diagnosis of OBPP was made on the basis of traumatic delivery as well as clinical findings of injury (including absence of active wrist extension). The age ranged from 4 to 18 years with mean 9.9 years. Eighteen patients were males and fourteen were females. Sixteen patients underwent tendon transfer to their Rt hand and the same number to Lt hand.

The donor tendon was FCU in most cases $(\mathrm{n}=25)$, also PT $(\mathrm{n}=3), \mathrm{BR}(\mathrm{n}=2), \operatorname{FDS}(\mathrm{n}=1)$ and PL $(n=1)$ were used. The recipient tendon was usually ECRB $(n=14)$ due to the ulnar deviation tendency of the wrist preoperatively, also EDC $(\mathrm{n}=12), \operatorname{ECRL}(\mathrm{n}=2), \operatorname{EPL}(\mathrm{n}=2)$ and FPL $(\mathrm{n}=2)$ were used.

Patients were followed-up at 3 rd $\&$ th weeks for wound healing and start of patient rehabilitation and $3 \mathrm{rd} \& 6$ th months post-operative for impact of the procedure on the hand function. Range of 
motion, Wrist and finger function using MRC, Toronto scale and Raimondi score.

\section{Surgical technique:}

Tendon transfer procedure is done under General Anaesthesia, different procedures were done (Table 1). An arm Torniquet was used. A longitudinal incision was done along the course of the tendon selected for the transfer. The tendon was detached near its insertion. Second longitudinal incision was done on the dorsal side of forearm. Tendons of recipient muscles were identified. A subcutaneous tunnel was made to dorsal side for selected tendon, usually ulnar but can be done also radial to improve ulnar deviation. The transferred tendon was sutured to the recipient tendon using Pulvertuft technique [5]. Wrist was held in splint for 4-6 weeks in 30 extension. After 4-6 weeks of immobilization, controlled motion was allowed with supervision by hand therapist. Full active use of the wrist was allowed 6-8 weeks after the operation.

Table (1): Different procedures done in the study.

\begin{tabular}{|c|c|c|c|}
\hline Donor & Recipient & $\begin{array}{l}\text { Associated } \\
\text { procedures }\end{array}$ & $\begin{array}{l}\text { No. of } \\
\text { cases }\end{array}$ \\
\hline $\mathrm{FCU}$ & EDC & & 9 \\
\hline FCU & ECRB & & 8 \\
\hline FCU & ECRB & Derotation Osteotomy & 2 \\
\hline FCU & ECRL & $\longrightarrow$ & 2 \\
\hline FCU & $\mathrm{EDC}$ & Fract lengthening of flexors & 1 \\
\hline FCU & EDC & Derotation Osteotomy & 1 \\
\hline FCU & ECRB & Common digital $n$. to ulnar $n$. & 1 \\
\hline FCU & EDC & PT to ECRB/PL to EPL & 1 \\
\hline PT & ECRB & $\longrightarrow$ & 1 \\
\hline PT & ECRB & MCP Capsulotomy & 1 \\
\hline PT & ECRB & PQTenotomy & 1 \\
\hline BR & FPL & & 1 \\
\hline $\mathrm{BR}$ & FPL & CMC Fusion \& Derot. Osteotomy & 1 \\
\hline FDS & EPL & & 1 \\
\hline PL & EPL & - & 1 \\
\hline
\end{tabular}

\section{Results}

Hand grip strength post operative ranged from $50 \%$ to $85 \%$ with mean of $71.1 \%$.

Raimondi score ranged preoperative from zero to 3 with mean of 1 while postoperative ranged from 2 to 5 with mean of 3.78 and mean gain of 2.78 .

Preoperative wrist extension ranged from zero to 4 with mean of 1.2 according to modified MRC scale, from zero to 4 with average of 1.28 according to Toronto scale. Finger extension ranged from zero to 4 with mean of 2.31 according to modified MRC scale, from zero to 5 according to Toronto scale. The average ROM preoperative ranged from zero to 45 with mean 10.5 degrees for wrist extension and ranged from zero to 45 with mean of 31 degrees for finger extension.

Postoperative wrist extension ranged from 25 with mean of 3.75 according to modified MRC scale, from 3-6 with mean of 4.6 according to Toronto scale. Finger extension ranged from 3-4 with mean of 3.875 according to modified MRC scale and ranged from 4-5 with mean of 4.75 according to Toronto scale.

The ROM postoperative ranged from 20-70 with mean gain 43.4 degrees for wrist and ranged from 45-75 with mean gain of 24 degrees for fingers.

Results on average are satisfactory in $75 \%$ of cases (modified MRC > $>4$ ) and fair in 25\% (modified $\mathrm{MRC}<4)$.

Table (2): Summary of Results.

\begin{tabular}{|c|c|c|}
\hline Scale & Wrist & Fingers \\
\hline \multicolumn{3}{|l|}{ ROM: } \\
\hline Pre & $0-45$ (mean 10.5$)$ & $0-45($ mean 31$)$ \\
\hline Post & 20-70 (mean 53.9) & $45-75($ mean 65$)$ \\
\hline Gain & 43.4 degrees & 14 degrees \\
\hline \multicolumn{3}{|c|}{ Modified MRC: } \\
\hline Pre & $0-4$ (mean 1.2) & $0-4($ mean 2.31$)$ \\
\hline Post & $2-5($ mean 3.75$)$ & $3-4($ mean 3.875$)$ \\
\hline Gain & 2.55 & 1.65 \\
\hline \multicolumn{3}{|l|}{ Toronto: } \\
\hline Pre & $0-4$ (mean 1.28$)$ & $0-5$ (mean 3$)$ \\
\hline Post & $3-6($ mean 4.6$)$ & $4-5($ mean 4.75$)$ \\
\hline Gain & 3.3 & 1.75 \\
\hline \multicolumn{3}{|l|}{ Raimondi } \\
\hline Pre & 0-3 (mean 1 ) & \\
\hline Post & $2-5($ mean 3.78$)$ & \\
\hline Gain & 2.78 & \\
\hline Hand grip & $\begin{array}{l}50 \%-85 \% \text { of } \\
\text { normal side (mean } 71 \%)\end{array}$ & \\
\hline
\end{tabular}




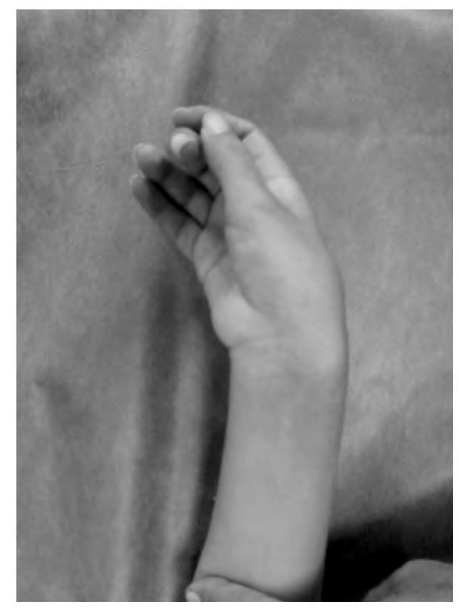

Fig. (1): Illustrative case, preoperative inability of active wrist extension \& ulnar deviation deformity.

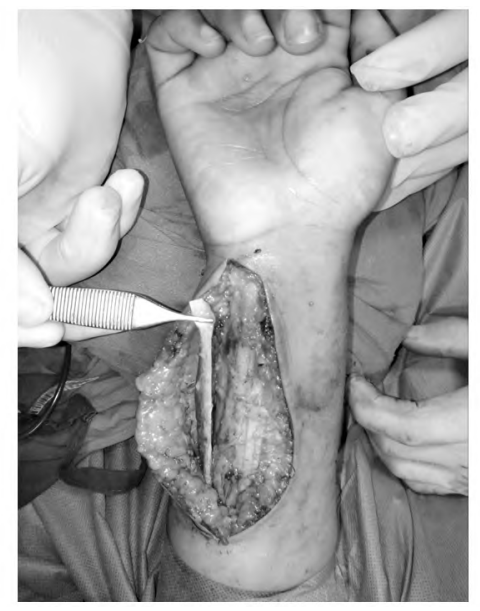

Fig. (2): Intraoperative transfer of FCU tendon to ECRL tendon.

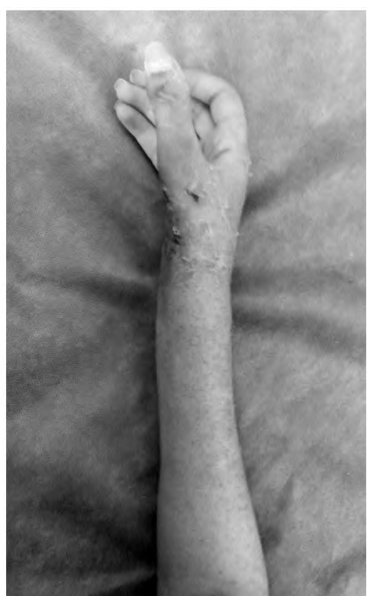

Fig. (3): Immediately after cast removal.
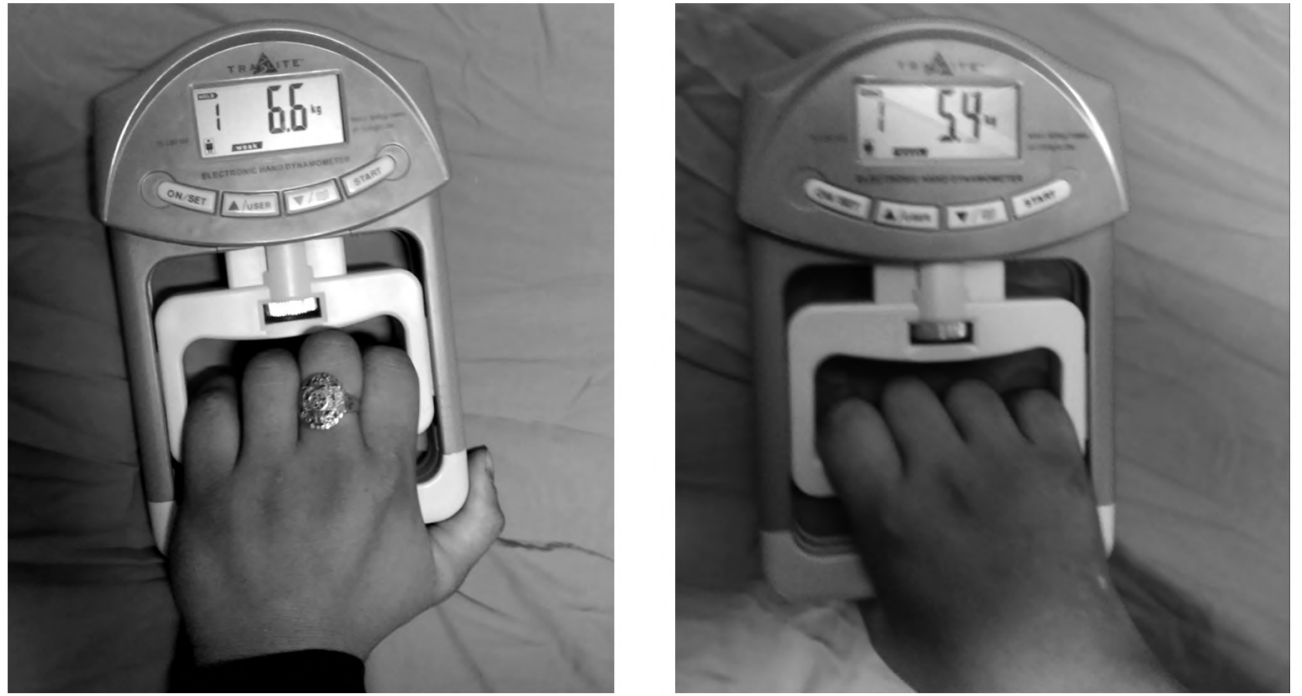

Figs. (4,5): 6 months- Follow up with dynamometer.

\section{Discussion}

FCU was usually taken as a donor tendon $(n=23)$. This provide the advantage to compensate for ulnar deviation that usually accompanies the deformity so this restores wrist balance as well as wrist power. PT is an alternative $(n=3)$ depending on the Tendon transfer is considered as a surgical option in case of inadequate spontaneous neurological recovery or residual functional deficits after microsurgical brachial plexus exploration.

In case of previous microsurgical brachial plexus exploration, 2 years should pass to assure that no further recovery would occur so tendon transfer can be done if the recovery is not satisfactory.

Supple wrist \& radioulnar joints are mandatory before tendon transfer otherwise wrist fusion; chondrodesis or arthrodesis (in older patients) should be carried out. The choice of tendon transfer for reconstruction of wrist extension depends on the availability of suitable muscles that strength of it. FDS was used in injuries involving C5-7 roots in which pronator teres and wrist flexors were weak [6]

The choice of the extensor tendon also determined by muscle strength, usually to the central wrist extensor; ECRB [7] transfer to ECRB in our study done in 13 cases. The extent of finger extension is an important factor that if unsatisfactory, would recommend the use of EDC to restore some finger extension as well as wrist extension $(\mathrm{n}=11)$.

The presence of thumb deformity as the main obstacle for hand function necessitates isolated transfer to the thumb (in 2 cases EPL was the 
recipient tendon while in other 2 cases FPL was the recipient one).

Duclos and Gilbert found similar clinical results after pronator, FCU, or FCR transfers in children with upper trunk injuries; however, they advocated use of FCU in the global palsy group [8]

Al-Qattan studied retrospectively 20 children over 7 year-priod with obstetric brachial plexus palsy palsy who underwent tendon transfer to reconstruct wrist extension. The flexor carpi ulnaris was utilized 15 times and the flexor carpi radialis in five times. The transferred tendon was sutured to the tendon of the extensor carpi radialis brevis. The result of the transfer was assessed according to a modified Medical Research Council (MRC) muscle grading system. A good result was obtained in 18 patients (modified MRC grade of 4 ) and a fair result (modified MRC grade of 3) in two [9].

David studied over a 10-year period, 21 children (11 males, 10 females) underwent tendon transfer to restore active wrist extension. Donor tendons included the flexor carpi ulnaris (FCU) $(n=14)$, brachioradialis $(n=4)$, and pronator teres $(n=3)$. The recipient was the extensor carpi radialis brevis in all cases. Preoperatively all patients demonstrated complete wrist drop (grade 0). Postoperative, the average result based on the modified Duclos and Gilbert scale was 2.14. At latest follow-up, 14 $(66 \%)$ children demonstrated active wrist extension of more than grade 2.3 patients demonstrated static extension of the wrist [3].

Van alven underwent a retrospective study reviewed the transfer of the flexor carpi ulnaris (FCU) or flexor carpi radialis (FCR) to the extensor carpi radialis brevis (ECRB) and/or longus (ERCL) to reconstruct wrist extension in 19 patients with obstetric brachial plexus palsy (OBPP). Preoperatively, none of the patients had active wrist extension, with an average wrist extension-lag of 37.4 (SD 15.1) degrees. Postoperatively, average active wrist extension was 9.2 (SD 25.5) degrees. Average gain in wrist extension was 46.6 (SD 28.2) degrees [2].

Wolf et al., reported 16 cases of tendon transfer of the FCU to ECRB or ECRL in children with (OBPP). This transfer provided wrist extension and treated ulnar deviation of the wrist. Transfer changes the rest position and the range of motion to a more neutral/extended position. The average extension after 4-year follow-up was $9^{\circ}$ and all patients felt a definite improvement in wrist function [10].
Finally, it should be appreciated that in many children with severe brachial plexus birth injury that involves the hand, the role of a tendon transfer for wrist dorsiflexion is often palliative. Achieving maximum hand function will involve additional carefully selected procedures based on ongoing recovery.

\section{Compliance with ethical standards \\ Ethics:}

No ethical conflict and no financial support were present or received upon writing, editing, or sending the present work.

\section{Conflict of interest:}

The authors declare that they have no conflict of interest.

\section{References}

1- O'BRIEN D.F., PARK T.S., NOETZEL M.J. and WEATHERLY T.: Management of birth brachial plexus palsy. Childs Nerv Syst. Feb., 22 (2): 103-12, 2006.

2- N.A. VAN ALPHEN, M.H. VAN DOORN-LOOGMAN, H. MAAS, J.A. VAN DER SLUIJS and M.J.P.F. RITTA: Journal of Pediatric Rehabilitation Medicine: An Interdisciplinary Approach, 6: 53-57, 2013.

3- DAVID E., RUCHELSMAN W., LORNA E., RAMOS M.A., OTR/L Z.Y., ANDREW E., PRICE Z., et al.: Outcome After Tendon Transfers to Restore Wrist Extension in Children With Brachial Plexus Birth Injuries, J. Pediatr. Orthop., 31: 455-457, 2011.

4- AL-QATTAN M.M.: Obstetric brachial plexus palsy associated with breech delivery. Ann. Plast. Surg. Sep., 51 (3): 257-64, discussion 265, 2002.

5- PULVERTAFT R.G.: Suture Materials and Tendon Junctures. Am. J. Surg., 109 (3): 346-352, 1965.

6- BEACH W.R., STRECKER W.B., COE J., MANSKE P.R., SCHOENECKER P.L., DAILEY L.: Use of the Green transfer in treatment of patients with spastic cerebral palsy: 17-year experience. J. Paediatr. Orthop., 11: 731736, 1991.

7- DUNNET W.J., HOUSDEN P.L., BIRCH R.: Flexor to extensor tendon transfers in the hand. J. Hand. Surg. Br., 20: 26-28, 1995.

8- DUCLOS L. and GILBERT A.: Restoration of wrist extension by tendon transfer in cases of obstetrical brachial plexus palsy. Ann. Chir. Main. Memb. Super., 18: 7-12, 1999.

9- AL-QATTAN M.M.: Tendon transfer to reconstruct wrist extension in children with obstetric brachial plexus palsy. J. Hand. Surg. Br., 28: 153-157, 2003.

10- WOLF T.M., CLINKSCALES C.M. and HAMLIN C.: Flexor carpi ulnaris tendon transfers in cerebral palsy. J. Hand. Surg. Br., 23 (3): 340-343, 1998. 


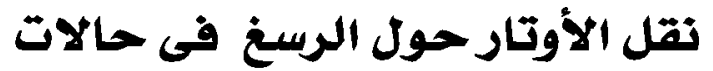

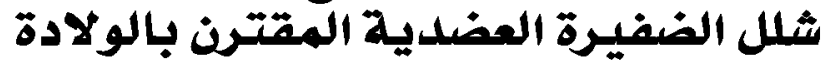

شلل الضفيرة العضدية المقترن بالولادة يعرف بأنه شلل رخو للذراع عند الولادة مع مدى الحركة السلبى من مدى الحركة النشط.

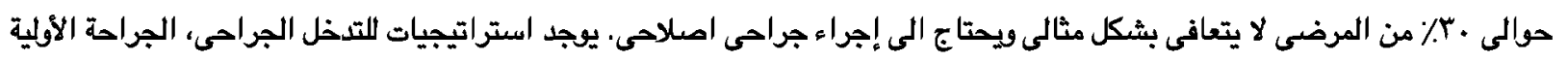

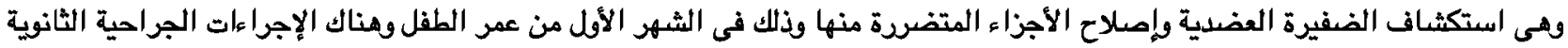
والتى منها الأوتار.

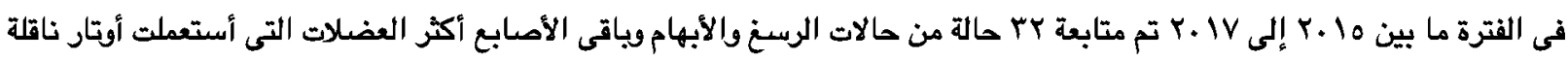

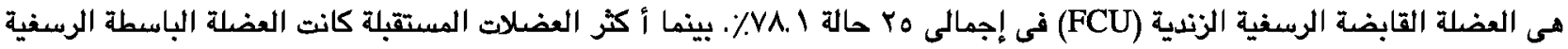

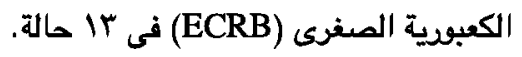

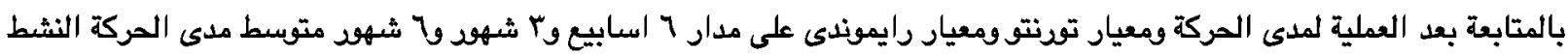

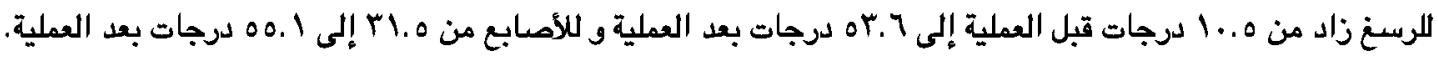

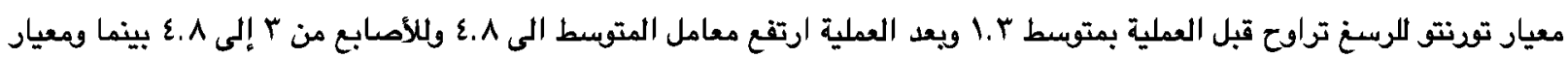

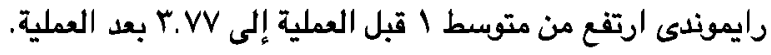
لم تتبين فروقات احصائية بإختلاف ناحية الأصابة نوع المريض اووقت العملية. تبينت نتائج أفضل بالإرتباط لعمر اقل عند إجراء الجراجة و بالإرتباط بنقل أوتار مسبق حل الكتف أو استكثاف مسبق للضفيرة العضدية فى مرحلة مبكرة من الحياة. 